\title{
A comparison in a youth population between those with and without a history of concussion using biomechanical reconstruction
}

\author{
Andrew Post, PhD, ${ }^{1,2}$ T. Blaine Hoshizaki, PhD, ${ }^{2}$ Michael D. Gilchrist, PhD, ${ }^{3}$ David Koncan, MSc, ${ }^{2}$ \\ Lauren Dawson, MSc, ${ }^{2}$ Wesley Chen, BScH, ${ }^{2}$ Andrée-Anne Ledoux, PhD, ${ }^{1}$ Roger Zemek, MD, ${ }^{1}$ and \\ the Pediatric Emergency Research Canada (PERC) 5P Concussion Team
}

${ }^{1}$ Children's Hospital of Eastern Ontario Research Institute, Ottawa, Canada; ${ }^{2 H u m a n}$ Kinetics, University of Ottawa, Canada; and ${ }^{3}$ School of Mechanical \& Materials Engineering, University College Dublin, Ireland

\begin{abstract}
OBJECTIVE Concussion is a common topic of research as a result of the short- and long-term effects it can have on the affected individual. Of particular interest is whether previous concussions can lead to a biomechanical susceptibility, or vulnerability, to incurring further head injuries, particularly for youth populations. The purpose of this research was to compare the impact biomechanics of a concussive event in terms of acceleration and brain strains of 2 groups of youths: those who had incurred a previous concussion and those who had not. It was hypothesized that the youths with a history of concussion would have lower-magnitude biomechanical impact measures than those who had never suffered a previous concussion.
\end{abstract}

METHODS Youths who had suffered a concussion were recruited from emergency departments across Canada. This pool of patients was then separated into 2 categories based on their history of concussion: those who had incurred 1 or more previous concussions, and those who had never suffered a concussion. The impact event that resulted in the brain injury was reconstructed biomechanically using computational, physical, and finite element modeling techniques. The output of the events was measured in biomechanical parameters such as energy, force, acceleration, and brain tissue strain to determine if those patients who had a previous concussion sustained a brain injury at lower magnitudes than those who had no previously reported concussion.

RESULTS The results demonstrated that there was no biomechanical variable that could distinguish between the concussion groups with a history of concussion versus no history of concussion.

CONCLUSIONS The results suggest that there is no measureable biomechanical vulnerability to head impact related to a history of concussions in this youth population. This may be a reflection of the long time between the previous concussion and the one reconstructed in the laboratory, where such a long period has been associated with recovery from injury.

https://thejns.org/doi/abs/10.3171/2016.10.PEDS16449

KEY WORDS concussion; history; biomechanics; youth; trauma

$\mathrm{C}$ ONCUSSIONS are described as a subset of traumatic brain injury (TBI), which is one of the most common injuries in pediatric emergency medicine. ${ }^{61}$ Children have been shown to undergo longer and more challenging recoveries after concussion, which may be attributed to their developing brains. ${ }^{58} \mathrm{~A}$ reported risk factor in suffering a concussion is a history of previous concussions. ${ }^{19,52}$ The theory behind this phenomenon is that damage to the neural tissues from the first concussion may re- sult in a long-term weakening of their resistance to further injury. ${ }^{45,51}$ This topic has been investigated primarily using animal and tissue models but has yet to have been examined using a biomechanical analysis of a human population, let alone a pediatric subgroup.

The relation between a previous history of concussions and the likelihood of incurring further concussions is a critical point in understanding and reducing the risk of pediatric concussions. Having multiple concussions has been

ABBREVIATIONS CFC = channel frequency class; $C S D M=$ cumulative strain damage measure; $M A D Y M O=$ mathematical dynamic model; $P C S=$ persistent concussive syndrome; PERC = Pediatric Emergency Research Canada; TBI = traumatic brain injury; UCDBTM = University College of Dublin Brain Trauma Model; VN = vinyl nitrile. SUBMITTED August 4, 2016. ACCEPTED October 26, 2016.

INCLUDE WHEN CITING Published online January 27, 2017; DOI: 10.3171/2016.10.PEDS16449. 
associated with long-term impairments such as behavioral deficits, changes in neuropathology, and degeneration of neural tissues. ${ }^{6,7}$ Freiss et al..$^{14}$ found that impact-induced head rotations after an initial injury led to poorer neuropathological and neurobehavioral outcomes, with an increase in structural white matter brain damage using a piglet model. In addition, neuropathological and neurobehavioral outcomes were more severe when a secondary impact rotation was applied 24 hours after an initial impact (in comparison with 7 days apart), supporting the theory that an initial insult leads to long-term effects that reduce the resistance of tissues to a secondary impact of the same magnitude. Effgen and Morrison ${ }^{11}$ examined the effect of repeated loading on cell slice cultures and found that there was a heightened sensitivity of the brain tissue following mild mechanical loading. From repeated loading of a youth model cell culture, described as equivalent to a 10-12-year-old human, there were increases in longterm potentiation deficits, astrogliosis, nitrite production, cell loss, and dendritic damage. This increased vulnerability was identified as lasting between 72 and 144 hours, depending on the structural or biochemical measures used to quantify the damage to the tissues. Giza and Hovda ${ }^{16}$ investigated the neurometabolic cascades following concussion and found that many of the metabolites following concussion persist from minutes to days following the initial loading of the tissues. Using a mouse model combined with MRI, Yang et al. ${ }^{60}$ found that improvement in brain morphology occurred at 7 days, with complete recovery at approximately 30 days. This disagreement between researchers concerning time to recovery from a head impact may be in part a result of different animal and tissue models and methods used, as well as dependent on the measurement variable to quantify the injury. What does seem to be consistent is that there is a period of vulnerability of the tissues to a secondary impact following the initial insult.

The animal and brain tissue research supports the epidemiological studies that have shown that athletes are more likely to incur a concussion if they have already received 1 or more in the same playing season. ${ }^{19,52}$ This phenomenon of the effect of previous concussions on the long-term vulnerability of neural tissues to resist impact loading has particular importance when considering return to play/activity guidelines for youth and sport, a topic that has received considerable debate (Berger M, "Repetitive head injury in sports," oral presentation at the National Neurotrauma Symposium, 2014). ${ }^{18,27,56}$ While there has been research examining the tissue and epidemiological theories surrounding vulnerability to concussion from multiple impacts, there has been a lack of research examining this phenomenon from a biomechanical perspective for a youth population. As youth commonly engage in sports and incur concussions in sporting environments, identifying any biomechanical vulnerability related to a history of concussions would be critical in the prevention and management of this type of injury. The purpose of this research was to conduct a biomechanical comparison in a youth population who had incurred a concussion and examine those who had a history of concussion versus those who did not. It was hypothesized that the youth with a history of concussion would have lower-magnitude biomechanical impact measures than those who had never suffered a previous concussion.

\section{Methods \\ Study Population}

The patients used in this study were collected from 9 pediatric emergency hospitals across Canada that belonged to the Pediatric Emergency Research Canada (PERC) network. This research was a prospective study, in which the data were collected prospectively using a standardized data collection form. Patients between the ages of 5 and 18 years old who were diagnosed with a concussion as defined by the Zurich consensus statement were accepted into this study. ${ }^{28}$ Inclusion and exclusion criteria for these patients were previously described by Zemek et al. ${ }^{61}$ To conduct a biomechanical reconstruction of the impacts to the youths that resulted in concussion, an analysis of the impacts was completed using information from a standardized patient intake form. To be included in the biomechanical analysis the reconstruction information must have had a measurement of the height fallen (head to ground), age, sex, location of impact on the head, and impact surface (concrete, ice, etc.). A description of the type of event was also necessary, such as a fall or collision. Because subject position and velocities of impact could not be accounted for in collision-type impacts, only falling events were reconstructed to minimize error; falls from both sporting and nonsporting environments were included. To be included in this research the falls must have been described as a direct fall to a surface, and not a collision with the boards or goalposts from a fall. In addition to this information, knowledge of the presence of a helmet was required, along with the make and model. For this study, cases were divided into two groups: a "history" group that contained those with a previous history of at least 1 previous diagnosed concussion, and a "no history" group containing patients with no previously diagnosed concussions. This represented the separation of groups for the biomechanical analysis and allowed for a comparison with determination if the group with a history of brain injury received their most recent concussion at lower magnitudes of brain response than individuals who had no history of the injury.

\section{Testing Procedure}

To examine the concussion cases resulting from falling, each impact was reconstructed biomechanically using a combination of mathematical dynamic models (MADYMOs), physical reconstruction, and finite element analysis of the brain. This methodology has been used in the past to examine the biomechanics of impact for adult TBI, transient concussion, and persistent concussive syndrome (PCS) cases from hospital data sets..$^{10,38,39,44,43}$ It has been used by researchers to determine magnitudes of response and biomechanical vulnerability that may exist for different TBI lesions ${ }^{10,39,43}$ and to establish the range of brain tissue deformation that is associated with PCS in adults. ${ }^{38,44}$ As a result, this method has been found to have sufficient sensitivity to investigate the biomechanics 
of impacts for falling events, although this research would be the first to attempt to use this method for a pediatric population. In terms of accuracy, while there is no current state data on strain available for known impact loading conditions of a living human brain, this method has been found to produce similar magnitudes of brain strain response as has been described in anatomical tissue injury research. ${ }^{2,12,33,50}$ Using the description that was recorded on the patient intake form, MADYMO simulations of the kinematics of impact were used to determine the head contact velocities for the impact event. These inbound velocities, along with the description of impact location and impact surface, were then used as parameters for the drop test using a monorail drop rig (Fig. 1). An appropriately sized Hybrid III headform (Humanetics; Table 1) was chosen to represent the size of the head of the child at the time of impact using the child's age on the patient intake form. The headform was then attached to the monorail drop rig by an unbiased neckform and dropped onto the defined impact surface (concrete, turf, ice, or hardwood). The unbiased neck was a neck composed of symmetrical rubber and aluminum discs similar to that of the Hybrid III neckform, but without the bias to headform response. If a helmet was involved, a helmet identical or of similar energy-absorbing liner design (typically vinyl nitrile [VN] or expanded polypropylene) and composition was fitted to the headform for the impact test. Accelerometers in the headform captured the head's linear and rotational time histories from impact. These acceleration time histories were then used as input into the finite element model of the human brain to determine the maximum principal strain of the brain tissue from impact. Because a range of velocities was calculated from MADYMO, the high- and low-limit velocities were chosen to be reconstructed and 3 impacts were completed per velocity, per patient fall reconstruction.

\section{Equipment}

\section{Monorail Drop Rig System}

The monorail drop rig system was used to reconstruct

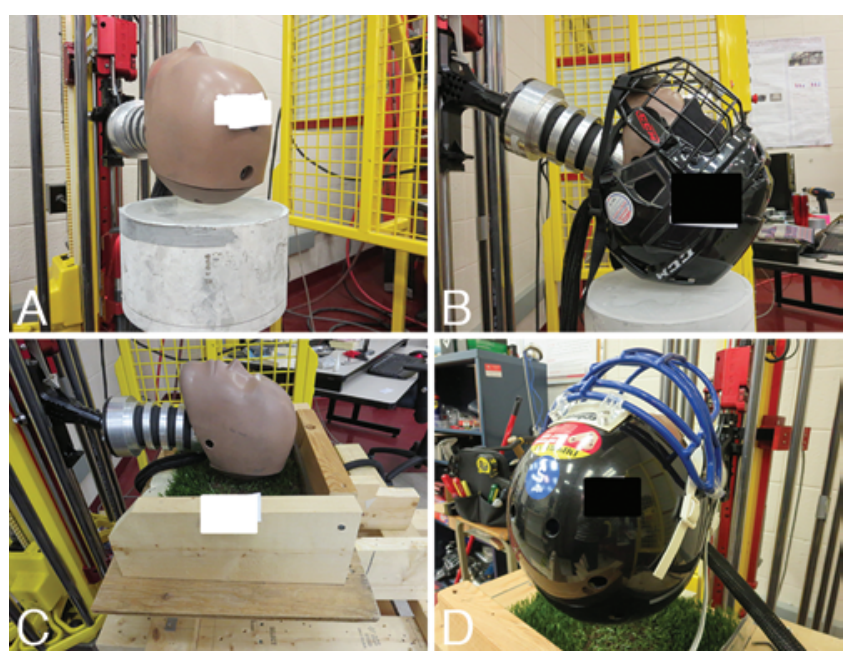

FIG. 1. Monorail impact reconstructions for fall to ice (A), fall to ice in youth ice hockey $(B)$, fall to turf in youth soccer $(C)$, and fall to turf in youth Canadian football (D). Figure is available in color online only.
TABLE 1. The Hybrid III headforms used for each age range as described in the literature

\begin{tabular}{lccc}
\hline $\begin{array}{c}\text { Hybrid III } \\
\text { Headform Model }\end{array}$ & $\begin{array}{c}\text { Circumference } \\
\text { Range }(\mathrm{cm})\end{array}$ & $\begin{array}{c}\text { Male Age } \\
(\mathrm{yrs})\end{array}$ & $\begin{array}{c}\text { Female Age } \\
(\mathrm{yrs})\end{array}$ \\
\hline 6-yr-old & $0-52.9$ & $6-7$ & $6-9$ \\
\hline 5th percentile & $52.9-56.4$ & $8-16$ & $10-18$ \\
\hline 50th percentile & $56.4-59.0$ & $17-18$ & \\
\hline
\end{tabular}

the falling brain injury events. The monorail drop rig used in this study was $4.7 \mathrm{~m}$ long with a pneumatically controlled release lever responsible for the release of the carriage. The Hybrid III headform was attached to this carriage by an unbiased neckform and was able to be positioned in $5^{\circ}$ of freedom to capture proper impact location as described on the patient intake form. The anvils used in this study included: concrete, ice, turf, hardwood, and steel. An ice anvil was created for impacts using a circular container ( $0.096 \mathrm{~m}$ deep, $0.204 \mathrm{~m}$ circumference) that was filled with water and frozen at $-25^{\circ} \mathrm{C}$ for 48 hours. To maintain surface consistency, the anvil was removed after impact and placed in a freezer for 5 minutes between each impact. A turf anvil was created using a $0.26 \mathrm{~m} \times 0.31 \mathrm{~m}$ $\times 0.05$ square of field turf. The hardwood anvil was composed of hardwood flooring panels attached to a standard subfloor and reinforced with 2- $\times 6$-inch supports to maintain a rigid structure for impact. A time gate placed 0.02 $\mathrm{m}$ before impact was used to capture the impact velocity.

\section{Hybrid III Headforms}

One of 3 Hybrid III headforms was used for each fall reconstruction. The headforms included a 6-year-old's headform representing the children, 5th percentile headform for the pre-teen to teenage group, and lastly a 50th percentile headform representing the oldest category (male teenagers). The headform selection for each case was determined from the size and mass of the patients in comparison with head circumference data within the literature (Table 1). ${ }^{24,35,37,65}$ Each headform was equipped with 9 Endevco (7264C-2KTZ-2-300) accelerometers positioned in a 3-2-2-2 array ${ }^{40}$ that measured the linear and rotational accelerations of the head from impact with a frame of reference: $x$-axis forward, y-axis to the left of the head, and z-axis upwards. Data were collected and recorded by 1 dedicated computer running DTS TDAS software systems (DTS). The filters used for the impacts varied depending on headform, with signals from impacts to the 50th percentile headform conditioned using a channel frequency class (CFC) 1000 filter and the 6-year-old's and 5th percentile headforms with a CFC 180 filter.

\section{Helmets}

All data collected for this study were categorized as a recreational or sporting fall. The sports examined in this study included: soccer, basketball, ice hockey, and Canadian football. For ice hockey and Canadian football, helmets were fitted to the headform as all players were wearing one when the concussion occurred. For the ice hockey reconstructions, an appropriately sized (small or medium) VN helmet and mask was used and for the football recon- 
structions, a youth VN helmet with a SKYDEX liner and mask was worn. The same helmet was used for multiple event reconstructions, with the impact location marked with a 5-cm-diameter circle to prevent overlap of testing locations. The helmet was replaced with a new model when an overlap occurred. Additionally, the response and physical condition of the helmet was continually monitored to ensure helmet performance did not diminish from repeated testing. ${ }^{5}$ A helmet was replaced if visible cracks in the shell or liner were found or if degradation in the protective capacity of the helmet was occurring as indicated through an unexplained increase in acceleration responses.

\section{MADYMO}

MADYMO is a computational tool commonly used to simulate falls and pedestrian accidents in the automotive industry. ${ }^{1}$ It is often used to recreate pedestrian incidents based upon eyewitness and subject reports. ${ }^{9,13,39,43}$ The benefit of this technique is that it allows for an improved estimation of head contact velocity because the kinematics of the event can be simulated. ${ }^{9,13,39,44}$ The strength of this program comes from its use of ellipsoid models that were validated for pedestrian impacts. ${ }^{57}$ The ellipsoid models were developed using anthropometrics that closely represented the weight and height of the pediatric patients. These models were then placed into a virtual environment that represented the situation in which the injury occurred. A series of simulations were conducted from the event description using the joint angles and positions as described or estimated from the patient intake form. Multiple simulations of impact scenarios were run for a sensitivity analysis as variations in eyewitness and subject accounts may have occurred., ${ }^{9,13,44}$ The model's head contact velocity from the simulations was used to define the upper and lower head velocities that were used to reconstruct the impact. Only the low-velocity head impacts as defined by the MADYMO simulations were analyzed for this research as they represent the lower boundary of when the injury occurred. ${ }^{44}$

\section{Finite Element Model}

Finite element analysis was conducted to determine the maximum principal strain in the cerebrum for an impact. The model used in this study was the University College of Dublin Brain Trauma Model (UCDBTM).,22 The geometry of this model was based on medical imaging of an adult male cadaver. The sections taken from the imaging that were incorporated into the model included scalp, skull, pia, falx, tentorium, CSF, gray and white matter, cerebellum, and the brainstem; ${ }^{23}$ these sections total approximately 26,000 elements.

Cadaveric anatomical and tissue sample research was used to determine the material properties of the model ${ }^{26,48,59,62,64}$ and are described in Tables 2 and 3. These tissues of the brain were modeled using a linearly viscoelastic model combined with large deformation theory that represented the behavior of the brain tissues, which is characterized as viscoelastic in shear with a deviatoric stress rate dependent on the shear relaxation modulus. ${ }^{22}$ The compression of the brain was defined as elastic. The
TABLE 2. Material properties for UCDBTM

\begin{tabular}{lccc}
\hline Material & $\begin{array}{c}\text { Young's Modulus } \\
(\mathrm{MPa})\end{array}$ & $\begin{array}{c}\text { Poisson's } \\
\text { Ratio }\end{array}$ & $\begin{array}{c}\text { Density } \\
\left(\mathrm{kg} / \mathrm{m}^{3}\right)\end{array}$ \\
\hline Dura & 31.5 & 0.45 & 1130 \\
\hline Pia & 11.5 & 0.45 & 1130 \\
\hline Falx & 31.5 & 0.45 & 1140 \\
\hline Tentorium & 31.5 & 0.45 & 1140 \\
\hline CSF & Water & 0.5 & 1000 \\
\hline Gray matter & Hyperelastic & 0.49 & 1060 \\
\hline White matter & Hyperelastic & 0.49 & 1060 \\
\hline
\end{tabular}

shear characteristic of the viscoelastic brain was expressed in the following equation: $\mathrm{G}(\mathrm{t})=\mathrm{G}_{\infty}+\left(\mathrm{G}_{0}-\mathrm{G}_{\infty}\right) e^{-\beta \mathrm{t}}$, in which $\mathrm{G}_{\infty}$ represents the long-term shear modulus, $\mathrm{G}_{0}$ the short-term modulus, and $\beta$ the decay factor. A MooneyRivlin hyperelastic material model was used for the brain to maintain these properties along with a viscoelastic material property in ABAQUS (Dassault Systèmes), with a decay factor of $\beta=145 \mathrm{~s}^{-1}$.22 The hyperelastic law was represented by the following formula: $\mathrm{C}_{10}(\mathrm{t})=0.9 \mathrm{C}_{01}(\mathrm{t})=$ $620.5+1930 e^{-t / 0.008}+1103 e^{-t / 0.15}(\mathrm{~Pa})$, in which $\mathrm{C}_{10}$ is the mechanical energy absorbed by the material when the first strain invariant changes by a unit step input, $\mathrm{C}_{01}$ is the energy absorbed when the second strain invariant changes by a unit step, ${ }^{29,31}$ and $t$ is the time in seconds. The skullbrain interaction was described as sliding with no separation between the CSF and the pia. The CSF was modeled by using solid elements with a bulk modulus of water and a low shear modulus. ${ }^{23,22}$ The coefficient of friction for the sliding interface was $0.2 .{ }^{32}$

Validation of the model was fulfilled by associating the UCDBTM's responses to the cadaveric-pressure time histories from impacts conducted by Nahum et al. ${ }^{34}$ Brain motion validations were completed with comparisons to the cadaveric impacts of Hardy et al. ${ }^{20}$ Further comparisons of model response were completed using brain injury reconstructions from real-life incidents by Doorly, ${ }^{9}$ Doorly and Gilchrist, ${ }^{10}$ Rousseau, ${ }^{47}$ and Post et al., ${ }^{44}$ which provided a good agreement with the magnitudes of strain and stress in the literature.

\section{Brain Size Scaling}

Currently, there is no consensus as to how to represent the brain tissue characteristics for a youth finite element head model, with many researchers suggesting that the parameters are often found to be within the range of

TABLE 3. Material properties of brain tissue used in the UCDBTM

\begin{tabular}{ccc}
\hline & \multicolumn{2}{c}{ Shear Modulus $(\mathrm{kPa})$} \\
\cline { 2 - 3 } Brain Tissue & $\mathrm{G}_{0}$ & $\mathrm{G}_{\infty}$ \\
\hline Gray matter & 10 & 2 \\
\hline White matter & 12.5 & 2.5 \\
\hline Brain stem & 22.5 & 4.5 \\
\hline Cerebellum & 10 & 2 \\
\hline
\end{tabular}

In each sample the decay constant $\left(\mathrm{s}^{-1}\right)$ was 80 , and the bulk modulus was $2.19 \mathrm{GPa}$. 
adults. ${ }^{4,46,49}$ As a result of these considerations the UCDBTM was scaled to represent the geometry of the youth involved in this research, with 3 scaled versions representing the variance in ages of the patient population. The child age group consisted of males aged 6-7 years and females aged 6-9 years. This group was analyzed using a finite element model that was scaled to $90 \%$ of the original UCDBTM. This scaling was based upon MRI brain size data from an average of 6-year-old patients. ${ }^{54}$ The male cases that were 8-16 years old and the females that were 10-17 years old used a 95\% scaled UCDBTM. The scaling for this analysis was chosen based on MRI brain size data. ${ }^{30}$ The fit of both models was concentrated on the anterior-posterior and inferior-superior axes (within 1 standard deviation). The 17- and 18-year-old male impacts were modeled using the full-size UCDBTM.

\section{Measurement Variables and Statistical Analyses}

A comparison of the concussion "history" and "no history" groups was conducted using force, energy, peak resultant linear and rotational acceleration, maximum principal strain of the gray and white matter, and cumulative strain damage measure (CSDM) set at $10 \%$ and $20 \%$ strain. Force and energy were included as they are directly related to the severity of the impact. Peak resultant linear acceleration has been demonstrated to be closely associated with certain mechanisms of TBI and skull fracture, ${ }^{17,53}$ whereas peak resultant rotational acceleration has been associated with the shearing of brain tissues believed to be the mechanism of concussion..$^{21,42}$ Maximum principal strain in the cerebrum was calculated, as this metric has been shown to be more closely associated with concussion than kinematic variables. ${ }^{2,25,42,63}$ The CSDM is a measure that examines how much of the brain tissues have passed a certain threshold of strain that is associated with structural or metabolic damage, in this case $10 \%$ and $20 \%$. The $10 \%$ measure was chosen based on the literature $^{15,41}$ demonstrating this magnitude to be predictive of concussion, while the $20 \%$ strain measure is indicative of structural damage in the tissues of the brain. ${ }^{2,33}$ To quantify the amount of the brain tissues that have passed these assigned thresholds, the number of elements that passed the value was determined and the percentage of the total number of elements in the cerebrum that this represented was calculated. As this is a slight modification of the original CSDM calculation, ${ }^{3}$ the CSDM in this research was termed $\mathrm{CSDM}^{\mathrm{e}-10}$ and $\mathrm{CSDM}^{\mathrm{e}-20}$, respectively.

The data were examined by comparing responses of the dependent variables for the "history" concussion group to the "no history" group using t-tests for the data set, with an $\alpha$ level set to 0.05 . Further analyses using binary logistic regression were also conducted to determine if there was a predictive variable able to distinguish between these groups.

\section{Results}

The total number of participants' data permitted into the study following inclusion/exclusion criteria was 3063. After the inclusion/exclusion criteria were applied, a total of 222 cases were analyzed for the biomechanical impact parameters and reconstructed in the laboratory. In total, 164 patients were reconstructed for the "no history" group and 58 for the "history" group. The "history" group had an average time interval of 864 days from the previous concussion to the one reported for this research (median 498 days). Those cases that were reconstructed were from several different impact environments, such as nonsport falls ( $\mathrm{n}=15$ [history], $\mathrm{n}=64$ [no history]), Canadian football ( $\mathrm{n}=4$ [history], $\mathrm{n}=11$ [no history]), $\operatorname{soccer}(\mathrm{n}=6$ [history], $\mathrm{n}=17$ [no history]), basketball ( $\mathrm{n}=5$ [history], $\mathrm{n}=19$ [no history]), and ice hockey ( $\mathrm{n}=28$ [history], $\mathrm{n}=$ 53 [no history]).

The results of the variables recorded for these impacts are presented in Figs. 2-5. When the data set was compared, no significant differences were found in any of the biomechanical variables between the "history" and "no history" groups $(\mathrm{p}>0.05)$. When binary logistic regression analyses were conducted for the purpose of determining a predictive variable and threshold between the 2 groups, no significance was found ( $\mathrm{p}>0.05)$.

\section{Discussion \\ History of Concussion}

The goal of this research was to compare the biomechanics of impact between a group of youths who had incurred a previous concussion to a group that had no previous history. The results of the reconstructions of the youth concussions did not reveal any statistical difference in biomechanical variables between the "history" and "no history" concussion groups. Large variations in response were present between patients within the impact environments (nonsport, soccer, etc.), which was reflected in the large standard deviations shown in the results. This variance is a reflection of the range in which an individual can incur a concussive injury in each environment. In effect, no consistent difference was found between the "history" and "no history" groups, even though research would suggest that the history of concussion group should have been injured at lower levels of magnitude of impact than the no history of concussion group. ${ }^{11,14}$ This result is likely a reflection of the impact event within each of these brain injury environments. In sport, the players engage in play within a certain framework governed by the field of play and rules of the sport that creates a corridor of velocity, mass, and compliance (helmets and padding) in which impacts most often occur. These parameters would cre-
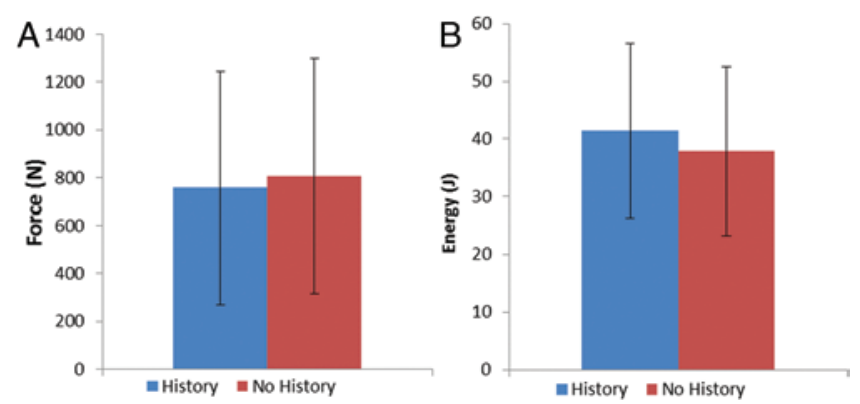

FIG. 2. Force (A) and energy (B) comparisons in the "history" and "no history" concussion groups for different injury environments. Error bars denote standard deviations. Figure is available in color online only. 

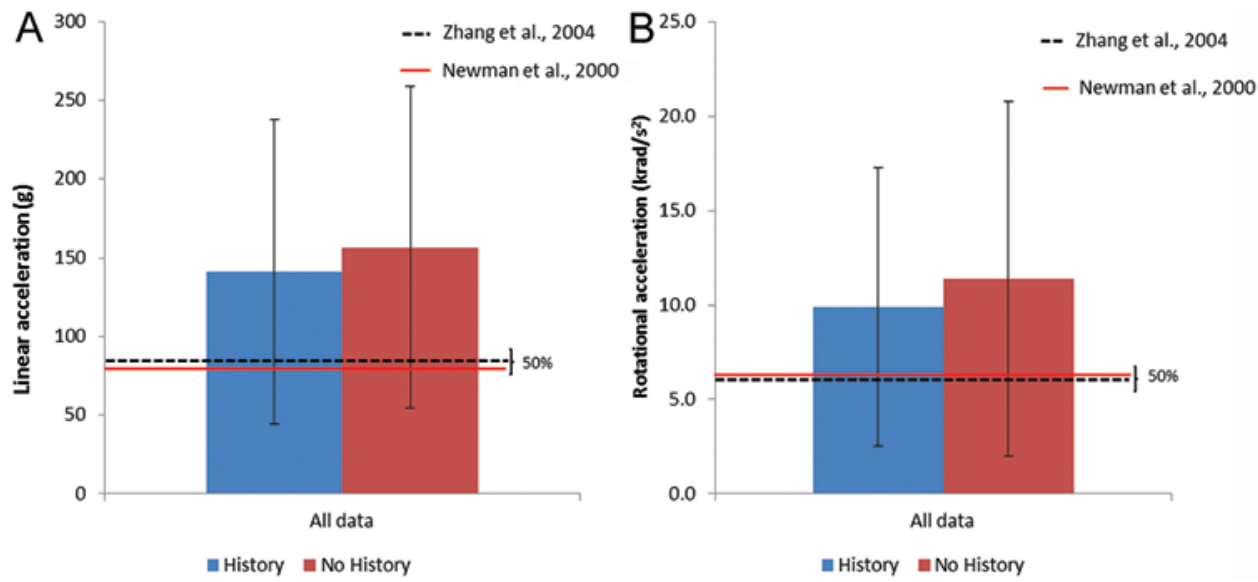

FIG. 3. Bar graphs showing peak linear acceleration (A) and peak resultant rotational acceleration (B) comparing the "history" and "no history" concussion groups for different injury environments with $50 \%$ risk of concussion from the literature. Error bars denote standard deviations. Figure is available in color online only.

ate an environment such that when an impact occurred, the characteristics of force, energy, and resulting head accelerations would result in injury regardless of previous history of concussion. This is reflected in the similarity in many of the measures when comparing the two groups. These real-world impact conditions lack the precision and control of animal investigations that have identified a vulnerability of brain tissues to the impact magnitude and time between injurious impacts. Because these factors cannot be controlled in this context, it makes it difficult to quantify a similar result in a human population, let alone a pediatric one that may have more variation due to different maturational status of the individuals. Beyond the lack of control that exists for human real-world impact reconstructions, there is inherent variability in using a multimodel approach that may occlude significant differences between the "history" and "no history" concussion groups. To reduce this variation, it may be useful to narrow investigations to examining certain types of impact conditions within 1 sporting risk environment instead of examining all environments, as was done in this research.

In addition, there was a considerable amount of time that had passed between the first reported concussion and the event reconstructed in this research. With such a large time frame between concussion events, it would be likely that the brain tissues would have recovered sufficiently that no vulnerability would have remained from the previous brain injury. ${ }^{52,55,56,60}$ Of the total "history" concussion group, only 2 cases had an injury interval (2.5 days and 13 days) that would fit within the vulnerability window described by the literature..$^{11,14,16}$ Even so, the impact mechanics of these 2 cases were indistinguishable from the other reconstructions. In summary, the impact events presented in this research would support the animal and tissue models that describe no vulnerability to incurring a concussion from an impact when the period of time between impacts is large. There is a link as shown by multiple research analyses using other models and methods that may be more appropriate to investigate this vulnerability in controlled timeframes and magnitudes of impact. .11, $14,16,52,55,56,60$ The limitation to those methods is that animal and tissue analysis are not as directly transferrable to human clinical practice. While there is some evidence that this vulnerability to concussion based on history of
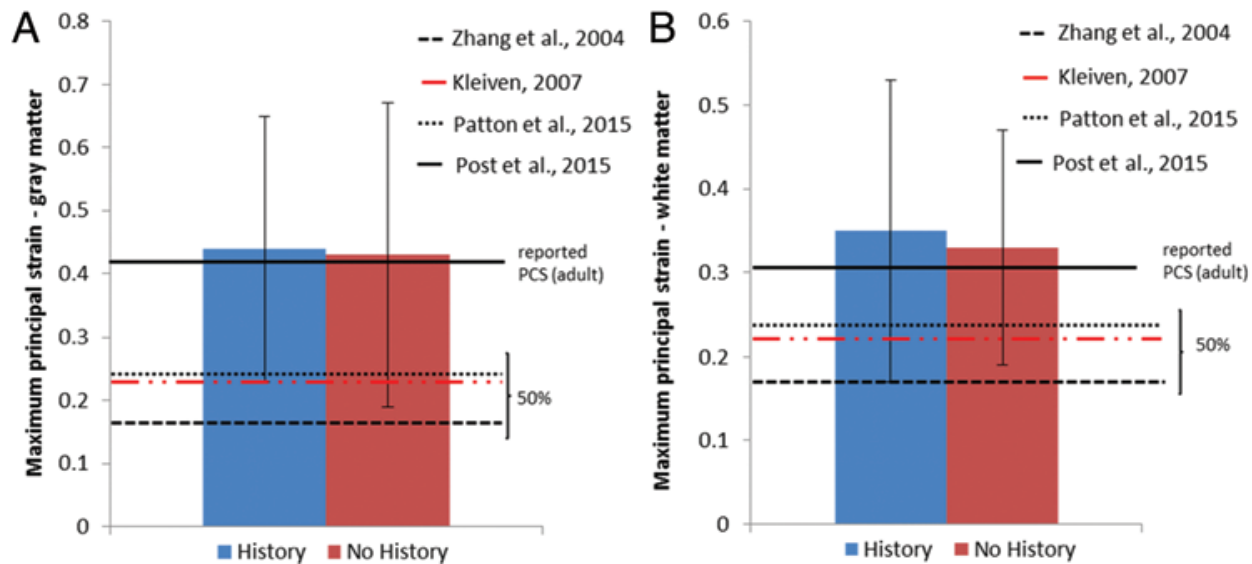

FIG. 4. Maximum principal strain for gray matter (A) and white matter (B) comparing the "history" and "no history" concussion groups for different injury environments with $50 \%$ risk of concussion from the literature. Error bars denote standard deviations. Figure is available in color online only. 

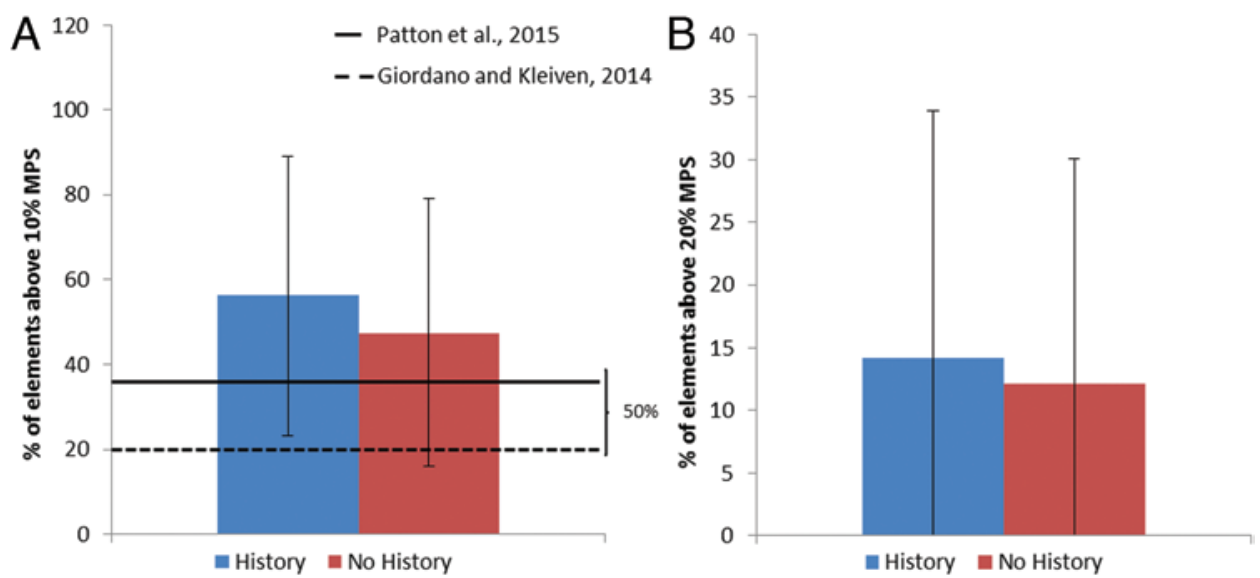

FIG. 5. $\operatorname{CSDM}^{\mathrm{e}-10}(\mathbf{A})$ and $\operatorname{CSDM}^{\mathrm{e}-20}$ (B) comparing the "history" and "no history" groups for different injury environments with $50 \%$ risk of concussion from the literature. Error bars denote standard deviations. Figure is available in color online only. MPS = maximum principal strain.

brain injury relationship may exist in humans, it has not been fully elucidated. This work is one of the first to investigate these phenomena in a large cohort of pediatric patients. While this work did not find any relationship, the durations between previous concussions and this analysis was so large that vulnerability would not be expected based on the literature. In the future, it may be more appropriate to examine repeated concussions in a narrower time frame or across different time frames if the data can be developed. In addition, focusing on sport environments of risk may be an ideal area to conduct this investigation as video may be available to increase the precision of the methods used.

In comparison with the literature that has described risk of concussion, the youth concussions reconstructed in this research resulted in large magnitude responses, responses well above those commonly associated with a risk of concussion. ${ }^{15,25,36,41,63}$ Considering the parameters of mass and velocity in these pediatric cases were below those of adults as a result of their smaller stature, ${ }^{44}$ these results might suggest a vulnerability of youth to incurring a brain injury at lower energies regardless of previous history of concussion. ${ }^{8}$

\section{Limitations of the Study}

This research was conducted using clinical patient reports and then conducting laboratory reconstructions to acquire approximations of the parameters that are commonly used to quantify severity of impact. The use of data from patient and eyewitness recollections can be affected by recall error, and while the ensuing methods attempt to account for this by creating a corridor of response, there is some error involved in these assumptions. This recall bias is a primary factor in creating the variance found in this research. Future studies should focus on methods to either reduce variance from recall/report forms, or use video where available. This research was developed from a large cohort of injury cases found across multiple emergency room departments (more than 3000 cases). To reduce the recall bias, strict inclusion criteria were used, which narrowed this sample to just 222 cases, but this bias cannot be completely eliminated. In addition, the reconstruction protocols use headforms and modeling methods that are representative of general human anthropometrics and tissue characteristics for the respective age ranges in this research, but are not biofidelic to each individual that was injured. To gain insight into the biomechanics of impact for the population, general models are used that can then be transferred into injury prevention programs, protective equipment development, and standards. These models that were used (computational, finite element, and physical) have limitations in that they are a general representation of the populations, but may not fully represent the variation in maturational status of these pediatric patients in this research, even though effort was made to match the head sizes and brain sizes as closely as possible.

\section{Conclusions}

The reconstructions of 222 youth concussion cases demonstrated that there was no clear vulnerability created by having a history of concussion when quantified by biomechanical measures. This result may be a reflection of the long time interval between the previous concussion and the one reconstructed in this study (median 498 days), which is well beyond the timeframes that describe a metabolic and mechanical vulnerability in the brain tissues. As a result, this research demonstrates that there may be no difference in vulnerability in youth engaging in sport and nonsport activities when there is a long period of time between concussive events.

\section{Appendix}

The collaborators for the PERC 5P Concussion Team were as follows: Candice McGahern, BA; Gurinder Sangha, MD; Darcy Beer, MD; William Craig, MDCM; Ken J. Farion, MD; Angelo Mikrogianakis, MD; Karen Barlow, MD; Alexander S. Dubrovsky, MDCM, MSc; Willem Meeuwisse, MD, PhD; William P. Meehan III, MD; Yael Kamil, BSc; Anne M. Grool, MD, PhD, MSc; Blaine Hoshizaki, PhD; Peter Anderson, PhD; Brian L. Brooks, PhD; Michael Vassilyadi, MDCM, MSc; Terry Klassen, MD; Michelle Keightley, PhD; Lawrence Richer, MD; and Carol DeMatteo, MSc. 


\section{Acknowledgments}

This study was funded by a Canadian Institutes of Health Research Operating Grant (TM1, no. 127047) and Canadian Institutes of Health Research-Ontario Neurotrauma Foundation Mild Traumatic Brain Injury Team Grant (no. 126197).

\section{References}

1. Adamec J, Jelen K, Kubovy P, Lopot F, Schuller E: Forensic biomechanical analysis of falls from height using numerical human body models. J Forensic Sci 55:1615-1623, 2010

2. Bain AC, Meaney DF: Tissue-level thresholds for axonal damage in an experimental model of central nervous system white matter injury. J Biomech Eng 122:615-622, 2000

3. Bandak FA, Eppinger RH: A three-dimensional finite element analysis of the human brain under combined rotational and translational accelerations, in Proceedings of the 38th Stapp Car Crash Conference. Warrendale, PA: Society of Automotive Engineers, 1994, pp 145-163

4. Chatelin S, Constantinesco A, Willinger R: Fifty years of brain tissue mechanical testing: from in vitro to in vivo investigations. Biorheology 47:255-276, 2010

5. Cournoyer J, Post A, Rousseau P, Hoshizaki B: The ability of American football helmets to manage linear acceleration with repeated high-energy impacts. J Athl Train 51:258263, 2016

6. Daneshvar DH, Nowinski CJ, McKee AC, Cantu RC: The epidemiology of sport-related concussion. Clin Sports Med 30:1-17, vii, 2011

7. Daneshvar DH, Riley DO, Nowinski CJ, McKee AC, Stern RA, Cantu RC: Long-term consequences: effects on normal development profile after concussion. Phys Med Rehabil Clin N Am 22:683-700, ix, 2011

8. Dawson L: Impact Characteristics Describing Concussive Injury in Youth [master's thesis]. Ottawa: University of Ottawa, 2016

9. Doorly MC: Investigations Into Head Injury Criteria Using Numerical Reconstruction of Real Life Accident Cases [doctoral thesis]. Dublin: University College Dublin, 2007

10. Doorly MC, Gilchrist MD: The use of accident reconstruction for the analysis of traumatic brain injury due to head impacts arising from falls. Comput Methods Biomech Biomed Engin 9:371-377, 2006

11. Effgen GB, Morrison B III: Electrophysiological and pathological characterization of the period of heightened vulnerability to repetitive injury in an in vitro stretch model. $\mathbf{J}$ Neurotrauma [epub ahead of print], 2016

12. Elkin BS, Morrison B III: Region-specific tolerance criteria for the living brain. Stapp Car Crash J 51:127-138, 2007

13. Forero Rueda MA, Gilchrist MD: Comparative multibody dynamics analysis of falls from playground climbing frames. Forensic Sci Int 191:52-57, 2009

14. Friess SH, Ichord RN, Ralston J, Ryall K, Helfaer MA, Smith $\mathrm{C}$, et al: Repeated traumatic brain injury affects composite cognitive function in piglets. J Neurotrauma 26:1111-1121, 2009

15. Giordano C, Kleiven S: Evaluation of axonal strain as a predictor for mild traumatic brain injuries using finite element modeling. Stapp Car Crash J 58:29-61, 2014

16. Giza CC, Hovda DA: The neurometabolic cascade of concussion. J Athl Train 36:228-235, 2001

17. Gurdjian ES, Lissner HR, Webster JE, Latimer FR, Haddad BF: Studies on experimental concussion: relation of physiologic effect to time duration of intracranial pressure increase at impact. Neurology 4:674-681, 1954

18. Guskiewicz KM, Bruce SL, Cantu RC, Ferrara MS, Kelly JP, McCrea M, et al: Research based recommendations on management of sport related concussion: summary of the National Athletic Trainers' Association position statement. Br J Sports Med 40:6-10, 2006

19. Guskiewicz KM, McCrea M, Marshall SW, Cantu RC, Randolph C, Barr W, et al: Cumulative effects associated with recurrent concussion in collegiate football players: the NCAA Concussion Study. JAMA 290:2549-2555, 2003

20. Hardy WN, Foster CD, Mason MJ, Yang KH, King AI, Tashman S: Investigation of head injury mechanisms using neutral density technology and high-speed biplanar X-ray. Stapp Car Crash J 45:337-368, 2001

21. Holbourn AHS: Mechanics of head injuries. Lancet 242:438-441, 1943

22. Horgan TJ, Gilchrist MD: The creation of three-dimensional finite element models for simulating head impact biomechanics. Int J Crash 8:353-366, 2003

23. Horgan TJ, Gilchrist MD: Influence of FE model variability in predicting brain motion and intracranial pressure changes in head impact simulations. Int J Crash 9:401-418, 2004

24. Júlíusson PB, Roelants M, Nordal E, Furevik L, Eide GE, Moster D, et al: Growth references for $0-19$ year-old Norwegian children for length/height, weight, body mass index and head circumference. Ann Hum Biol 40:220-227, 2013

25. Kleiven S: Predictors for traumatic brain injuries evaluated through accident reconstructions. Stapp Car Crash J 51:81114,2007

26. Kleiven S, von Holst $\mathrm{H}$ : Consequences of head size following trauma to the human head. J Biomech 35:153-160, 2002

27. Makdissi M, McCrory P, Ugoni A, Darby D, Brukner P: A prospective study of postconcussive outcomes after return to play in Australian football. Am J Sports Med 37:877-883, 2009

28. McCrory P, Meeuwisse WH, Aubry M, Cantu B, Dvorák J, Echemendia RJ, et al: Consensus statement on concussion in sport: the 4th International Conference on Concussion in Sport held in Zurich, November 2012. Br J Sports Med 47:250-258, 2013

29. Mendis KK, Stalnaker RL, Advani SH: A constitutive relationship for large deformation finite element modeling of brain tissue. J Biomech Eng 117:279-285, 1995

30. Mennes M, Jenkinson M, Valabregue R, Buitelaar JK, Beckmann C, Smith S: Optimizing full-brain coverage in human brain MRI through population distributions of brain size. Neuroimage 98:513-520, 2014

31. Miller K, Chinzei K: Constitutive modelling of brain tissue: experiment and theory. J Biomech 30:1115-1121, 1997

32. Miller R, Margulies SS, Leoni M, Nonaka M, Chen X, Smith $\mathrm{D}$, et al: Finite element modeling approaches for predicting injury in an experimental model of severe diffuse axonal injury, in Proceedings of the 42nd Stapp Car Crash Conference. Warrendale, PA: Society of Automotive Engineers, 1990, pp 155-166

33. Morrison B III, Cater HL, Wang CCB, Thomas FC, Hung CT, Ateshian GA, et al: A tissue level tolerance criterion for living brain developed in an In Vitro model of traumatic mechanical loading. Stapp Car Crash J 47:93-105, 2003

34. Nahum AM, Smith R, Ward C: Intracranial pressure dynamics during head impact, in Proceedings of 21st Stapp Car Crash Conference. Warrendale, PA: Society of Automotive Engineers, 1977, p 337

35. Nellhaus G: Head circumference from birth to eighteen years. J Am Academy Ped 41:106, 1968

36. Newman JA, Shewchenko N, Welbourne E: A proposed new biomechanical head injury assessment function: the maximum power index, in Proceedings of the 44th Stapp Car Crash Conference. Warrendale, PA: Society of Automotive Engineers, 2000, pp 215-247

37. Nguyen AKD, Simard-Meilleur AA, Berthiaume C, Godbout $\mathrm{R}$, Mottron L: Head circumference in Canadian male adults: 
development of a normalized chart. Int J Morphol 30:14741480,2012

38. Oeur RA, Karton C, Post A, Rousseau P, Hoshizaki TB, Marshall S, et al: A comparison of head dynamic response and brain tissue stress and strain using accident reconstructions for concussion, concussion with persistent postconcussive symptoms, and subdural hematoma. J Neurosurg 123:415422, 2015

39. O'Riordain K, Thomas PM, Phillips JP, Gilchrist MD: Reconstruction of real world head injury accidents resulting from falls using multibody dynamics. Clin Biomech (Bristol, Avon) 18:590-600, 2003

40. Padgaonkar AJ, Kreiger KW, King AI: Measurement of angular acceleration of a rigid body using linear accelerometers. J Appl Mech 42:552-556, 1975

41. Patton DA, McIntosh AS, Kleiven S: The biomechanical determinants of concussion: Finite element simulations to investigate tissue-level predictors of injury during sporting impacts to the unprotected head. J Appl Biomech 31:264268, 2015

42. Post A, Hoshizaki TB: Rotational acceleration, brain tissue strain, and the relationship to concussion. J Biomech Eng 137:030801, 2015

43. Post A, Hoshizaki TB, Gilchrist MD, Brien S, Cusimano MD, Marshall S: The influence of dynamic response and brain deformation metrics on the occurrence of subdural hematoma in different regions of the brain. J Neurosurg 120:453-461, 2014

44. Post A, Kendall M, Koncan D, Cournoyer J, Hoshizaki TB, Gilchrist MD, et al: Characterization of persistent concussive syndrome using injury reconstruction and finite element modelling. J Mech Behav Biomed Mater 41:325-335, 2015

45. Prins ML, Alexander D, Giza CC, Hovda DA: Repeated mild traumatic brain injury: mechanisms of cerebral vulnerability. J Neurotrauma 30:30-38, 2013

46. Roth S, Vappou J, Raul JS, Willinger R: Child head injury criteria investigation through numerical simulation of real world trauma. Comput Methods Programs Biomed 93:3245, 2009

47. Rousseau P: An Analysis of Dynamic Concussion Metrics Associated With Elite Ice Hockey Elbow-to-Head and Shoulder-to-Head Collisions [doctoral thesis]. Ottawa: University of Ottawa, 2014

48. Ruan JS: Impact Biomechanics of Head Injury by Mathematical Modeling [doctoral thesis]. Detroit: Wayne State University, 1994

49. Ruan SJ, Li PD, Li HY, Zhao W: Development and validation of a 6-year-old child finite element head model. Zhongguo Shengwu Yixue Gongcheng Xuebao 31:1-12, 2012

50. Schreiber DI, Bain AC, Meaney DF: In vivo thresholds for mechanical injury to the blood brain barrier, in Proceedings of the 41st Stapp Car Crash Conference. Warrendale, PA: Society of Automotive Engineers, 1997, pp 277-291

51. Slemmer JE, Weber JT: The extent of damage following repeated injury to cultured hippocampal cells is dependent on the severity of insult and inter-injury interval. Neurobiol Dis 18:421-431, 2005

52. Slobounov S, Slobounov E, Sebastianelli W, Cao C, Newell $\mathrm{K}$ : Differential rate of recovery in athletes after first and second concussion episodes. Neurosurgery 61:338-344, 2007

53. Thomas LM, Roberts VL, Gurdjian ES: Experimental intracranial pressure gradients in the human skull. J Neurol Neurosurg Psychiatry 29:404-411, 1966

54. Uchiyama HT, Seki A, Tanaka D, Koeda T: A study of the standard brain in Japanese children: morphological comparison with the MNI template. Brain Dev 35:228-235, 2013
55. Vagnozzi R, Signoretti S, Tavazzi B, Floris R, Ludovici A, Marziali S, et al: Temporal window of metabolic brain vulnerability to concussion: a pilot ${ }^{1} \mathrm{H}$-magnetic resonance spectroscopic study in concussed athletes-part III. Neurosurgery 62:1286-1296, 2008

56. Vagnozzi R, Tavazzi B, Signoretti S, Amorini AM, Belli A, Cimatti M, et al: Temporal window of metabolic brain vulnerability to concussions: mitochondrial-related impairment-part I. Neurosurgery 61:379-389, 2007

57. van Hoof J, de Lange R, Wismans JSHM: Improving pedestrian safety using numerical human models. Stapp Car Crash J 47:401-436, 2003

58. Weeks D, Sullivan S, Kilbaugh T, Smith C, Margulies SS: Influences of developmental age on the resolution of diffuse traumatic intracranial hemorrhage and axonal injury. J Neurotrauma 31:206-214, 2014

59. Willinger R, Taled L, Pradoura P: Head biomechanics: from finite element model to the physical model. Proc IRCOBI 23:245-259, 1995

60. Yang Z, Wang P, Morgan D, Bruijnzeel AW, Lin D, Pan J, et al: Temporal MRI characterization, neurobiochemical and neurobehavioral changes in a mouse repetitive concussive head injury model. Sci Rep 5:11178, 2015 (Erratum in Sci Rep 5:15922, 2015)

61. Zemek R, Barrowman N, Freedman SB, Gravel J, Gagnon I, McGahern C, et al: Clinical risk score for persistent postconcussion symptoms among children with acute concussion in the ED. JAMA 315:1014-1025, 2016

62. Zhang L, Yang KH, King AI: Comparison of brain responses between frontal and lateral impacts by finite element modeling. J Neurotrauma 18:21-30, 2001

63. Zhang L, Yang KH, King AI: A proposed injury threshold for mild traumatic brain injury. J Biomech Eng 126:226236, 2004

64. Zhou C, Khalil TB, King AI: A new model comparing responses of the homogeneous and inhomogeneous human brain, in Proceedings of the 39th Stapp Car Crash Conference. Warrendale, PA: Society of Automotive Engineers, 1995, pp 121-136

65. Zong XN, Li H: Construction of a new growth references for China based on urban Chinese children: comparison with the WHO growth standards. PLoS One 8:e59569, 2013

\section{Disclosures}

The authors report no conflict of interest concerning the materials or methods used in this study or the findings specified in this paper.

\section{Author Contributions}

Conception and design: Post, Hoshizaki, Zemek. Acquisition of data: Post, Koncan, Dawson, Chen. Analysis and interpretation of data: Post, Hoshizaki, Koncan, Dawson. Drafting the article: Post. Critically revising the article: all authors. Reviewed submitted version of manuscript: all authors. Approved the final version of the manuscript on behalf of all authors: Post. Statistical analysis: Post. Study supervision: Post, Hoshizaki, Zemek.

\section{Correspondence}

Andrew Post, Children's Hospital of Eastern Ontario Research Institute, 200 Lees Ave., Rm. A106, Ottawa, ON K1H 8L1, Canada.email: apost@uottawa.ca. 